\title{
EFFECT OF CONDITIONER ON DEWATERABILITY OF SEWAGE SLUDGE
}

\author{
J. I. Obianyo ${ }^{1}$ and J. C. Agunwamba ${ }^{2}$ \\ 1DEPARTMENT OF CIVIL ENGINEERING, ANAMBRA STATE UNIVERSITY, Uli, NIGERIA \\ 2DEPARTMENT OF CIVIL ENGINEERING, UNIVERSITY OF NIGERIA, NSUKKA, NIGERIA \\ E-mail addresses:1jiobianyo@yahoo.com, ${ }^{2}$ nwambaagu@yahoo.com
}

\begin{abstract}
A model for dewaterability of conditioned sludge was derived based on data generated after dewaterability experiments using six sand drying beds. In these experiments, Six beds were used, the first bed contain no conditioner and served as control experiment. Ferric Chloride was added to the remaining five beds in the neighborhood of $1 \%, 2 \%, 3 \%, 4 \%$, and $5 \%$ respectively, corresponding to $30 \mathrm{~g}, 60 \mathrm{~g}, 90 \mathrm{~g}, 120 \mathrm{~g}$ and $150 \mathrm{~g}$ of $\mathrm{FeCl}$ Seepage (sg) was derived as a linear function of time. The coefficient of correlation obtained from the linear regression of seepage against time corresponding to $30 \mathrm{~g}, 60 \mathrm{~g}, 90 \mathrm{~g}, 120 \mathrm{~g}$ and $150 \mathrm{~g}$ are $0.860,0.844,0.781,0.722$ and 0.535 respectively. Moisture content of sludge was $86.69 \%$ when no coagulant was added, it was $69.47 \%$, $57.32 \%, 54.01 \%, 52.79 \%$ and $47.81 \%$ when $30 \mathrm{~g}, 60 \mathrm{~g}, 90 \mathrm{~g}, 120 \mathrm{~g}$ and $150 \mathrm{~g}$ doses were used with a range of $38.88 \%$. Dewaterability enhancement ratio was 1:1 for control experiment, 1:27.72, 1:46.59, 1:51.72, 1:53.62 and 1:61.34 for $30 \mathrm{~g}, 60 \mathrm{~g}, 90 \mathrm{~g} 120 \mathrm{~g}$, and $150 \mathrm{~g}$ doses respectively. Statistical test parameter, "p-value" was computed for each coagulant dose and hypothesis tested at 95\% level of significance. The "p-value" results corresponding to $30 \mathrm{~g}, 60 \mathrm{~g}$. $90 \mathrm{~g}, 120 \mathrm{~g}$ and $150 \mathrm{~g}$ are $0.000,0.001,0.003,0.008$ and 0.073 . Based on the decision rule, it was concluded that the model is adequate. This model is good, but its deficiency lies in the fact that the coefficient of correlation between measured and calculated quantities of seepage at specified coagulant doses decrease with increase in coagulant dosage. Though, the higher the quantity of coagulant used, the higher the dewaterability of sewage sludge which is a big plus. The disadvantage of using coagulants in dewatering sludge lies in the fact that the effluent cannot be recycled for consumption because of the toxic Ferric Chloride that has been used as conditioner. It is recommended that further research be carried out to improve on this already existing model.
\end{abstract}

Key words: Conditioner, Dewaterability, Sewage sludge

\section{INTRODUCTION}

Dewatering is a physical unit operation used to reduce the moisture content of sludge and it is carried out for any of the following reasons: (a) to reduce cost of transportation of sludge to the ultimate disposal site when volume is reduced by dewatering (b) ease of handling (c) dewatering is normally required before incineration of sludge in order to increase the calorific value through removal of excess moisture (d) it may be required to remove excess moisture in order to render biosolids odourless and non putrescible (e) dewatering may be necessary before landfilling of sludge in order to reduce the leachate produced at the landfill site. Also, sludge produced in sewage treatment plant is raw, odorous and putrescible residue must be further processed and reduced in volume before ultimate disposal like land disposal or intermediate treatment like incineration. Common methods being mechanical dewatering after chemical conditioning, gravity or mechanical thickening. Usually, Ferric Chloride and Iron Chloro-Sulfate are mainly used in conjunction with lime to condition the sludge before a filter press. They allow a better filterability by coagulating the colloids (thus lowering the content of linked water) and by micro-flocculation of the precipitates (hydroxides). The dosages of iron salts are between $3 \%$ and $15 \%$ of the dry content, depending on the quality of sludge.

The approximate average capacity of a rural sewage facility is the domestic wastewater of 1000 persons [1], which is estimated to be approximately $300-330$

* Corresponding author, Tel: +234-703-133-7247 
$m^{3} d^{-1}$ of wastewater and municipal wastewater treatment plant serving large population huge volumes of wastewater is produced. These huge quantities need to be treated before disposal, otherwise it can give rise to environmental pollution and degradation. A by-product in the treatment of wastewater is the huge volume of sludge that needs to be disposed of. Sludge contains $0.25 \%$ to $16 \%$ solids and therefore to dispose of sludge economically its volume must be reduced. Sludge is generally conditioned before thickening and dewatering to improve their dewatering characteristics. The use of chemicals to condition sludge for dewatering has the capacity to reduce $90 \%$ of in-coming moisture content to 65 to $85 \%$ moisture content depending on the nature of the solids being treated. Two types of conditioning chemicals are used to enhance the treatability of the sludge and they are mineral salts such as iron salts and lime, and organic salts such as coagulants and flocculants. It has been discovered that an effective way of managing sewage sludge is by the use of conditioners such as coagulants. For instance, the production of potable water is conventionally carried out by coagulation with a hydrolyzing metal salt such as aluminum sulfate ('alum') or ferric chloride ('ferric'). This process is effective at removing turbidity, color and microorganisms, but also results in a waste by-product as the coagulants precipitate into particles that aggregate to form 'flocs' [2]. Settling of these flocs results in a sludge that can be thickened, centrifuged or filtered prior to ultimate disposal. These dewatering procedures reduce the volume of the waste stream, with both environmental and financial benefits. Also, the coagulation and flocculation processes in conventional drinking water treatment generate aggregates which settle to form a sludge waste. This sludge can be dewatered further by thickening, centrifugation and filtration operations in order to recover water and minimize the volume of the waste stream [2].

A phenomenological theory developed by [3] provides a rigorous approach to modeling the dewatering behavior of compressible materials, and has been adopted to model various dewatering unit operations [3]. Many models have been developed for settling of flocculent particles in suspension. In a series of papers [4-9], presented a phenomenological theory of sedimentation of flocculated suspensions, which provides a valuable framework for the simulation of batch and continuous thickening of suspensions. Also, in a numerical method introduced by [10], a software was developed for the simulation of batch and continuous thickening of suspensions.

Despite its unusual type-change feature, a variety of numerical methods can be employed in a straightforward manner to solve the governing equation and thereby to simulate the batch and continuous sedimentation processes [11]. An extensive introduction to suitable discretization techniques, including finite-difference and front tracking methods, is given by [12]. Particularly easy to implement is a finite-difference method that extends the so-called generalized upwind or Engquist and Osher method [13] to second -order, possibly degenerate, parabolic equations. This method was analyzed in detail by $[10$, $14]$.

\section{MATERIALS AND METHOD}

The essence of this experiment is to determine the effect of conditioner on dewaterability of sewage sludge. $2.0155 \mathrm{~g}$ sludge sample was oven dried at $105^{\circ} \mathrm{C}$, to enable determine the initial water content of the sludge. Result showed that moisture content was 81.01\%. 3000g of sewage sludge was used for this experiment and $1500 \mathrm{~g}$ of water was added to it thereby increasing the total weight to $4500 \mathrm{~g}$ thus, increasing the moisture content to $87.34 \%$, which implies that the total quantity of water in sludge in the six beds at the beginning of experiment is $0.8734 \times 4500=3930.30 \mathrm{~g}$, and further to that, the total quantity of water removed from the sludge at any given dose of conditioner were determined to enable the computation of dewaterability enhancement ratio (DER). DER is the ratio of maximum discharge at any given coagulant dose $(\gamma)$ to maximum discharge for control experiment $(\varepsilon)$. This ratio helps to make an inference as to the effect of any change in coagulant dose with respect to dewaterability. Anhydrous Ferric Chloride $\mathrm{FeCl}_{3}$ was used as the conditioner. These were thoroughly mixed and introduced into the drying beds for dewatering. The drying bed is funnel-shaped, $420 \mathrm{~mm}$ surface diameter, $340 \mathrm{~mm}$ vertical depth and fitted with a $25 \mathrm{~mm}$ diameter drain pipe. Six beds were used, the first bed contain no conditioner and served as control experiment. Ferric Chloride was added to the remaining five beds in the neighborhood of $1 \%, 2 \%$, $3 \%, 4 \%$, and $5 \%$ respectively, corresponding to $30 \mathrm{~g}$, $60 \mathrm{~g}, 90 \mathrm{~g}, 120 \mathrm{~g}$, and $150 \mathrm{~g}$ of $\mathrm{FeCl}_{3}$ and discharge from the bed were recorded at 1 hour intervals. The 
experimental set up and equipment used to conduct this research is shown in plate 1.

Assuming a linear relationship, instantaneous seepage $(s g)$ in conditioned sludge is given by the expression $s g=a+b t$, where " $a$ " and " $b$ " are the intercepts and slopes and $t$ is the time. To determine the values of the coefficients " $a$ " and " $b$ ", time was regressed on instantaneous seepage for each dose of $\mathrm{FeCl}_{3}$ coagulant added. Subsequently, different quantities of coagulant $Q$ was regressed on the different values of intercepts " $a$ ", where $a=\lambda_{1}+\lambda_{2} Q$ so as to determine the intercept $\lambda_{1}$ and the slope $\lambda_{2}$ of the above function. The same process was repeated for the slope " $b$ " in which $Q$ was regressed on the slope " $b "$, where $b=\beta_{1}+\beta_{2} Q$ so that the intercept $\beta_{1}$ and slope $\beta_{2}$ of this function to be determined.

It can now be shown that $s g=a+b t$, since $a=\lambda_{1}+\lambda_{2} Q$ and $b=\beta_{1}+\beta_{2} Q$, substituting these values into $s g=a+b t$ will give $s g=\left(\lambda_{1}+\lambda_{2} Q\right)+\left(\beta_{1}+\beta_{2} Q\right) t$. The later model was used to compute the calculated seepage $\left(s g_{c}\right)$ and governs dewaterability of conditioned sludge. At each dosage of conditioner used, measured seepage $\left(s g_{m}\right)$ was regressed on calculated seepage $\left(s g_{c}\right)$ to determine their correlations. Finally, statistical test parameter, "p-value" using the Pearson's correlation was computed for each coagulant dose and hypothesis was tested at 95\% level of significance. This parameter was used to make an inference as to whether model $s g=a+b t$ is adequate or not. Thus;

$H_{0}: P=0$ (The model $s g=a+b t$ is not adequate) $H_{1}: P \neq 0$ (The model $s g=a+b t$ is adequate)

At $95 \%$ level of significance, $(1-\alpha) 100=95$, $\Rightarrow \alpha=0.05$

Decision: Reject $H_{0}$ if $P$-value $<\alpha$, otherwise accept $H_{0}$

Test statistic

$t_{c a l}=\frac{r}{\sqrt{\left(\frac{1-r^{2}}{n-2}\right)} \text { for } n \leq 10}$
$z_{c a l}=\frac{z_{r}}{\sqrt{\left(\frac{1}{n-3}\right)}}$ for $n>10$

Where

$z_{r}=\frac{1}{2} \ln \left(\frac{1+r}{1-r}\right)$

$z_{r}$ is the transformation of the coefficient of correlation ' $r$ '

Since our sample size is greater than 10, then equation (2) was used to determine the p-values of the correlation between $s g_{m}$ and $s g_{c}$ corresponding to $30 \mathrm{~g}, 60 \mathrm{~g}, 90 \mathrm{~g}, 120 \mathrm{~g}$ and $150 \mathrm{~g}$ doses of $\mathrm{FeCl}_{3}$ coagulant used in the experiment

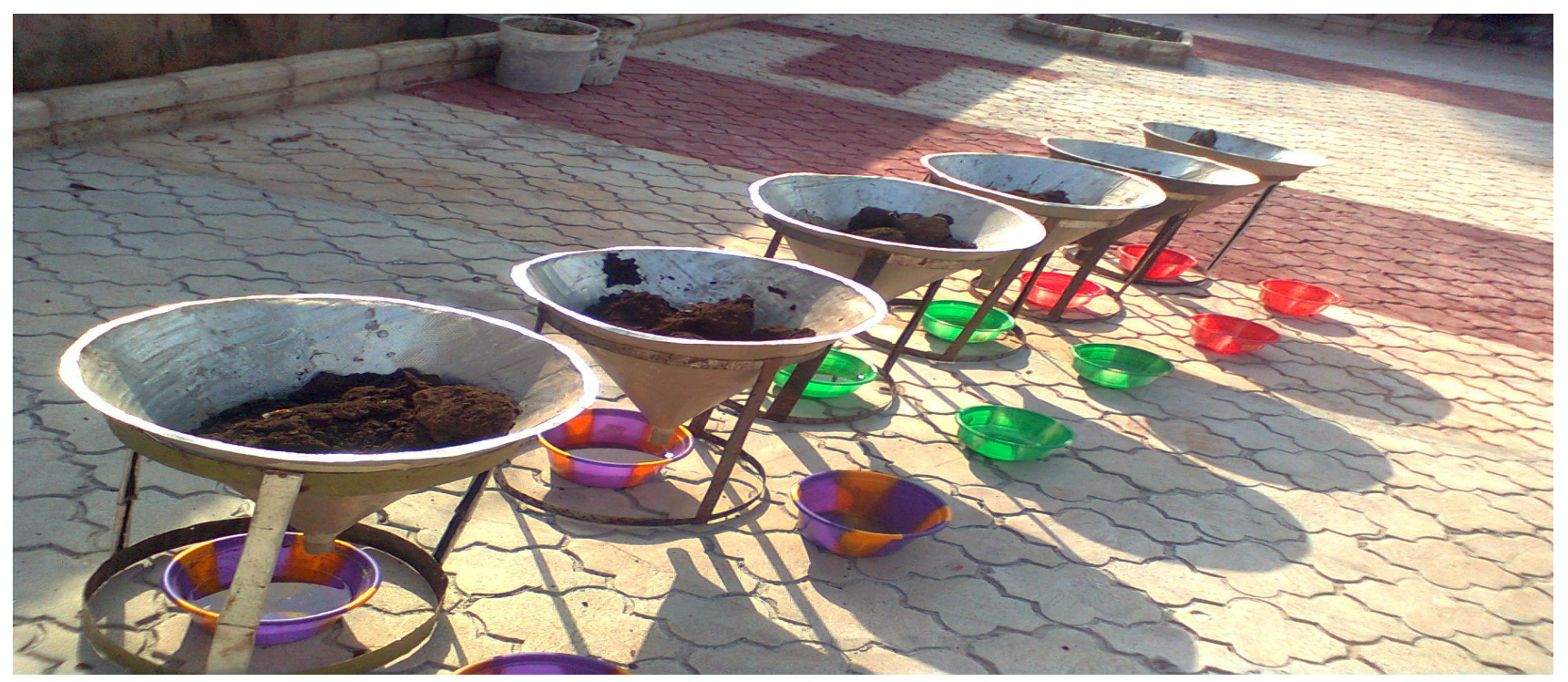

Plate 1: Experimental set-up for dewaterability of conditioned sludge 
Table 1: Relationship between instantaneous/cumulative seepage and time at different doses of coagulant

\begin{tabular}{|c|c|c|c|c|c|c|c|c|c|c|c|c|}
\hline \multirow{2}{*}{$\begin{array}{l}\text { Time } \\
\text { (hrs) }\end{array}$} & \multicolumn{2}{|c|}{$\begin{array}{c}\text { Control } \\
0.0 \mathrm{~g}(0 \%) \\
\mathrm{FeCl}_{3}\end{array}$} & \multicolumn{2}{|c|}{$\begin{array}{c}30 \mathrm{~g}(1.0 \%) \\
\mathrm{FeCl}\end{array}$} & \multicolumn{2}{|c|}{$\begin{array}{c}60 \mathrm{~g}(2.0 \%) \\
\mathrm{FeCl}\end{array}$} & \multicolumn{2}{|c|}{$\begin{array}{c}90 \mathrm{~g}(3.0 \%) \\
\mathrm{FeCl}_{3}\end{array}$} & \multicolumn{2}{|c|}{$\begin{array}{c}120 \mathrm{~g}(4.0 \%) \\
\mathrm{FeCl}_{3}\end{array}$} & \multicolumn{2}{|c|}{$\begin{array}{c}150 \mathrm{~g}(5.0 \%) \\
\mathrm{FeCl}_{3}\end{array}$} \\
\hline & $\begin{array}{l}\text { Inst. } \\
\text { Sg. }\end{array}$ & $\begin{array}{c}\text { Cum. } \\
\text { Sg. }\end{array}$ & $\begin{array}{l}\text { Inst. } \\
\text { Sg. }\end{array}$ & $\begin{array}{c}\text { Cum. } \\
\text { Sg. }\end{array}$ & $\begin{array}{l}\text { Inst. } \\
\text { Sg. }\end{array}$ & $\begin{array}{c}\text { Cum. } \\
\text { Sg. }\end{array}$ & $\begin{array}{l}\text { Inst. } \\
\text { Sg. }\end{array}$ & $\begin{array}{c}\text { Cum. } \\
\text { Sg. }\end{array}$ & $\begin{array}{c}\text { Inst. } \\
\text { Sg }\end{array}$ & $\begin{array}{c}\text { Cum. } \\
\text { Sg. }\end{array}$ & $\begin{array}{l}\text { Inst. } \\
\text { Sg. }\end{array}$ & $\begin{array}{c}\text { Cum. } \\
\text { Sg. }\end{array}$ \\
\hline 0 & 0 & 0 & 0 & 0 & 0 & 0 & 0 & 0 & 0 & 0 & 0 & 0 \\
\hline 1 & 0 & 0 & 150 & 150 & 479 & 479 & 664 & 664 & 779 & 779 & 1457 & 1457 \\
\hline 2 & 4 & 4 & 130 & 280 & 298 & 777 & 317 & 981 & 288 & 1067 & 119 & 1576 \\
\hline 3 & 4 & 8 & 107 & 387 & 194 & 971 & 188 & 1169 & 169 & 1236 & 59 & 1635 \\
\hline 4 & 3 & 11 & 68 & 455 & 116 & 1087 & 104 & 1273 & 96 & 1332 & 37 & 1672 \\
\hline 5 & 2 & 13 & 59 & 514 & 88 & 1175 & 84 & 1357 & 66 & 1398 & 29 & 1701 \\
\hline 6 & 2 & 15 & 47 & 561 & 62 & 1237 & 53 & 1410 & 50 & 1448 & 18 & 1719 \\
\hline 7 & 2 & 17 & 40 & 601 & 39 & 1276 & 37 & 1447 & 38 & 1486 & 15 & 1734 \\
\hline 8 & 2 & 19 & 42 & 643 & 23 & 1299 & 23 & 1470 & 24 & 1510 & 16 & 1750 \\
\hline 9 & 3 & 22 & 42 & 685 & 17 & 1316 & 13 & 1483 & 16 & 1526 & 13 & 1763 \\
\hline 10 & 3 & 25 & 41 & 726 & 14 & 1330 & 8 & 1491 & 12 & 1538 & 6 & 1769 \\
\hline 11 & 2 & 27 & 40 & 766 & 11 & 1341 & 6 & 1497 & 10 & 1548 & 6 & 1775 \\
\hline 12 & 2 & 29 & 38 & 804 & 10 & 1351 & 3 & 1500 & 7 & 1555 & 4 & 1779 \\
\hline
\end{tabular}

Table 2: Relationship between final moisture content of sludge and coagulant doses

\begin{tabular}{|c|c|c|c|c|c|c|}
\hline & $\begin{array}{c}\text { Control 0g } \\
\mathrm{FeCl}_{3} \\
(0 \%)\end{array}$ & $\begin{array}{c}30 \mathrm{~g} \mathrm{FeCl}_{3} \\
(1 \%)\end{array}$ & $\begin{array}{c}60 \mathrm{~g} \\
\mathrm{FeCl}_{3} \\
(2 \%)\end{array}$ & $\begin{array}{c}90 \mathrm{~g} \mathrm{FeCl}_{3} \\
(3 \%)\end{array}$ & $\begin{array}{c}120 \mathrm{~g} \\
\mathrm{FeCl}_{3} \\
(4 \%)\end{array}$ & $\begin{array}{c}130 \mathrm{~g} \\
\mathrm{FeCl}_{3} \\
(5 \%)\end{array}$ \\
\hline $\begin{array}{l}\text { Initial quantity of water in } \\
\text { sludge (g) }\end{array}$ & 3930.30 & 3930.30 & 3930.30 & 3930.30 & 3930.30 & 3930.30 \\
\hline $\begin{array}{l}\text { Maximum discharge at a given } \\
\text { coagulant dose }(\mathrm{g})\end{array}$ & 29.00 & 804.00 & 1351.00 & 1500.00 & 1555.00 & 1779.00 \\
\hline Weight of water remaining (g) & 3901.30 & 3126.30 & 2579.30 & 2430.30 & 2375.30 & 2151.30 \\
\hline Final moisture content (\%) & 86.69 & 69.47 & 57.32 & 54.01 & 52.79 & 47.81 \\
\hline
\end{tabular}

Table 3: Relationship between dewaterability enhancement ratio (DER) and coagulant doses

\begin{tabular}{|c|c|c|c|c|c|c|}
\hline & $\begin{array}{c}\text { Control 0g } \\
\mathrm{FeCl}_{3}(0 \%)\end{array}$ & $\begin{array}{c}30 \mathrm{~g} \\
\mathrm{FeCl}_{3} \\
(1 \%)\end{array}$ & $\begin{array}{c}60 \mathrm{~g} \\
\mathrm{FeCl}_{3} \\
(2 \%)\end{array}$ & $\begin{array}{c}90 \mathrm{~g} \\
\mathrm{FeCl}_{3} \\
(3 \%)\end{array}$ & $\begin{array}{c}120 \mathrm{~g} \\
\mathrm{FeCl}_{3} \\
(4 \%)\end{array}$ & $\begin{array}{c}130 \mathrm{~g} \\
\mathrm{FeCl}_{3} \\
(5 \%)\end{array}$ \\
\hline $\begin{array}{l}\text { Maximum discharge at any } \\
\text { given coagulant dose } \gamma(g)\end{array}$ & 29.0 & 804.0 & 1351.0 & 1500.0 & 1555.0 & 1779.0 \\
\hline $\begin{array}{l}\text { Maximum discharge for } \\
\text { control experiment } \varepsilon(g)\end{array}$ & 29.0 & 29.0 & 29.0 & 29.0 & 29.0 & 29.0 \\
\hline $\begin{array}{l}\text { Dewaterability enhancement } \\
\text { ratio }(\mathrm{DER})=\gamma / \mathcal{\varepsilon}\end{array}$ & 1.0 & 27.72 & 46.59 & 51.72 & 53.62 & 61.34 \\
\hline
\end{tabular}

\section{MATHEMATICAL DERIVATIONS}

3.1 Assumption: Linear relationship exist between instantaneous seepage and time in a conditioned sludge

The variation of instantaneous seepage (sg) with time $(\mathrm{t})$ is given by the expression;

$$
s g=a+b t
$$

Where $s g=$ seepage due to coagulation of sewage sludge, $a=$ intercept, $b=$ slope and $t=$ time. The values of $a$ and $b$ can be expressed linear functions of $Q$ as shown below;

$$
\begin{aligned}
& a=\lambda_{1}+\lambda_{2} Q \\
& b=\beta_{1}+\beta_{2} Q
\end{aligned}
$$

$\mathrm{Q}$ is the coagulant dose, $\lambda_{1}$ and $\lambda_{2}$ are the intercept and slope when different values of intercept $a$ were regressed with different doses of coagulant $Q$. 
$\beta_{1}$ and $\beta_{2}$ are the intercept and slope when different values of slope $b$ were regressed with different doses of coagulant $\mathrm{Q}$.

Substituting $\lambda_{1}+\lambda_{2}$ for " $a$ " and $\beta_{1}+\beta_{2}$ for " $b$ " in equation (1), we have

$s g=\left(\lambda_{1}+\lambda_{2} Q\right)+\left(\beta_{1}+\beta_{2} Q\right) t$

From the table of variation of $Q$ with $a$ we have that;

$\lambda_{2}=\frac{n \sum Q a-\sum Q \sum a}{n \sum Q^{2}-\left(\sum Q\right)^{2}}$

$\therefore \lambda_{2}=\frac{6(189998.115)-450(1804.3024)}{6(49500)-450^{2}}=3.471$

$\bar{a}=\lambda_{1}+\lambda_{2} \bar{Q}$

$\left(\frac{1804.3024}{6}\right)=\lambda_{1}+3.4707\left(\frac{450}{6}\right)$, or $\lambda_{1}=40.3921$

So that:

$a=40.3921+3.471 Q$

Also, from the table of variation of $Q$ with $b$, we have;

$\beta_{2}=\frac{n \sum Q b-\sum Q \sum b}{n \sum Q^{2}-\left(\sum Q\right)^{2}}$

$\beta_{2}=\frac{6(-20587.109)-450(-190.7517)}{6(49500)-450^{2}}=-0.3988$

$\bar{b}=\beta_{1}+\beta_{2} \bar{Q}$

$\left(\frac{-190.7517}{6}\right)=\beta_{1}-0.3988\left(\frac{450}{6}\right)$, or $\beta_{1}=-1.882$

So that: $b=-(1.882+0.3988 Q)$

But $s g=a+b t$

Substituting the values of $a$ and $b$ in (4) we have,

$s g=(40.3921+3.471 Q)-(1.882+0.3988 Q) t$

\subsection{Comparison of measured and Calculated Quantities of Seepage for conditioned sludge}

The model of (14) was used to determine calculated quantities of seepage for each dosage of $\mathrm{FeCl}_{3}$ coagulant (i.e. conditioner) used. At a given dose of coagulant $Q$, different times ranging from $t=1,2,3, \ldots \ldots . .12$ hours were substituted to determine the calculated quantities of seepage $s g_{c}$. Measured quantities of seepage $s g_{m}$ were regressed on the calculated quantities $s g_{c}$, and the coefficient of correlation $r$, gives a measure of adequacy of the model. Usually an $r$-value that tends to 1.0 good.

Table 4: P-values corresponding to correlations between $s g_{m}$ and $s g_{c}$

\begin{tabular}{ccc}
\hline \multirow{2}{*}{$\begin{array}{c}\text { Correlation between } \\
\text { dose }\end{array}$} & $\begin{array}{c}s g_{m} \text { and } s g_{c} \text { at various } \\
\text { doses }\end{array}$ & p-value \\
& 0.860 & \\
\hline 30 & 0.844 & 0.000 \\
60 & 0.781 & 0.001 \\
120 & 0.722 & 0.003 \\
120 & 0.535 & 0.008 \\
150 & & 0.073 \\
\hline
\end{tabular}

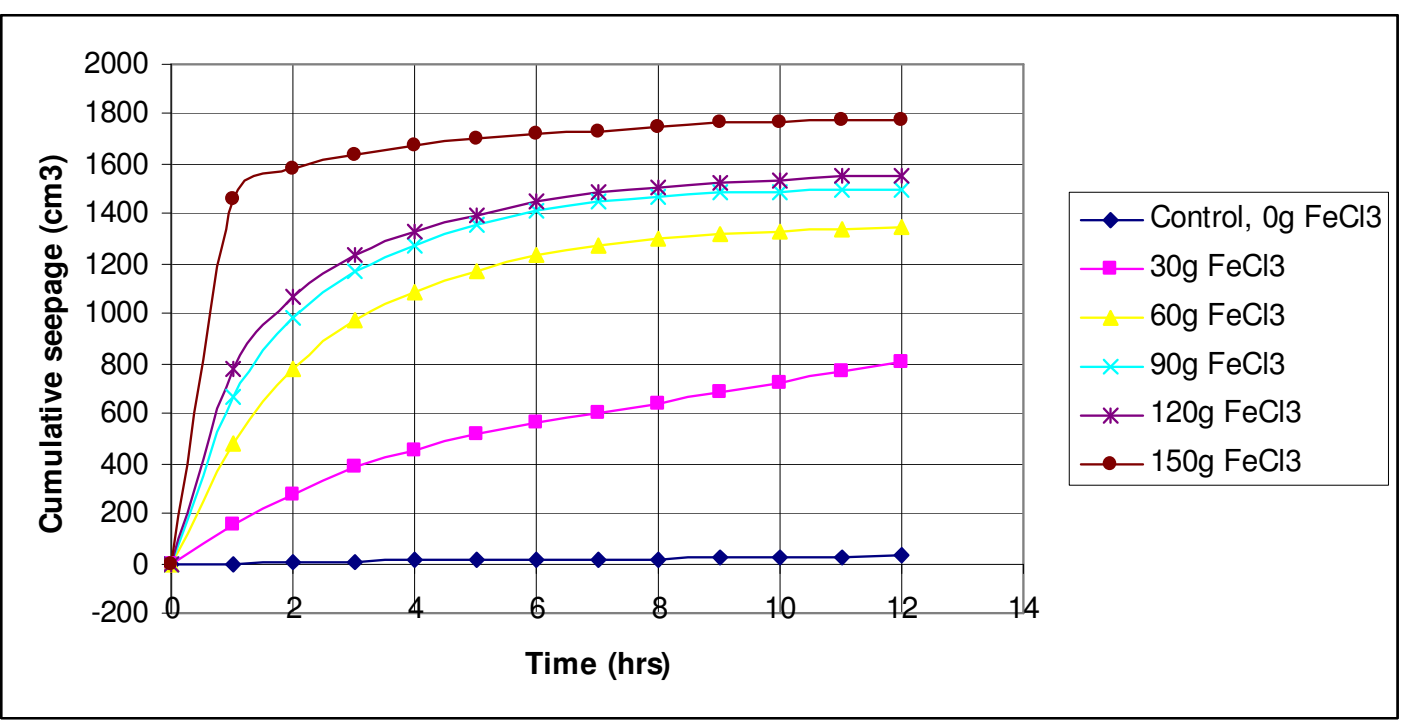

Figure 1 Variation of cumulative seepage with time at different doses of coagulant 


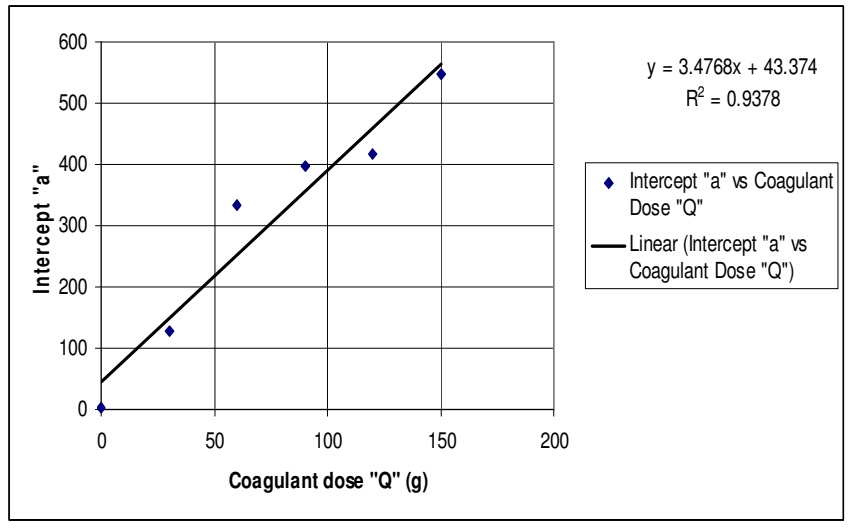

Figure 2: Variation of intercepts with coagulant doses

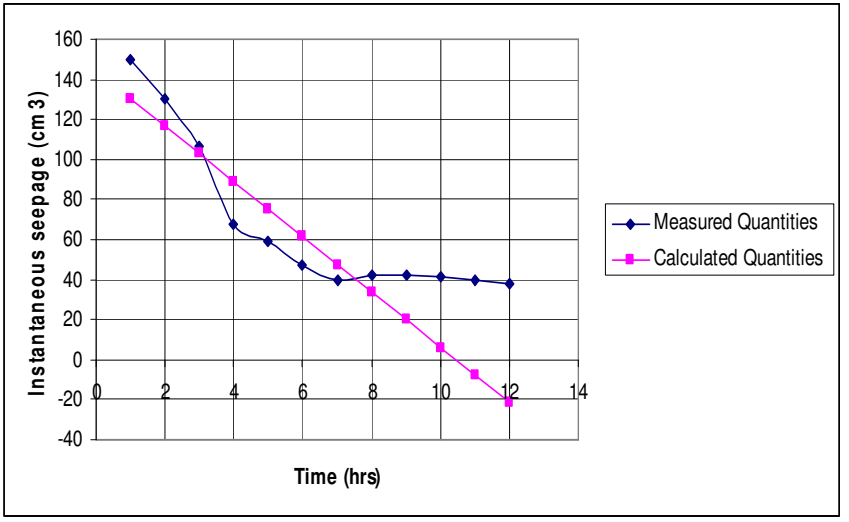

Figure 4: Comparison of measured and calculated Instantaneous seepage variation with time for $30 \mathrm{~g} \mathrm{FeCl}_{3}$ dose

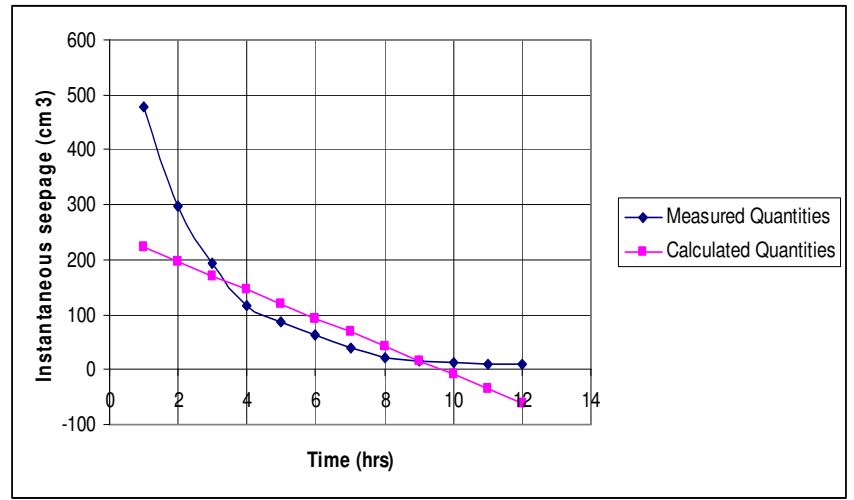

Figure 6: Comparison of measured and calculated Instantaneous seepage variation with time for $60 \mathrm{~g} \mathrm{FeCl}_{3}$ dose

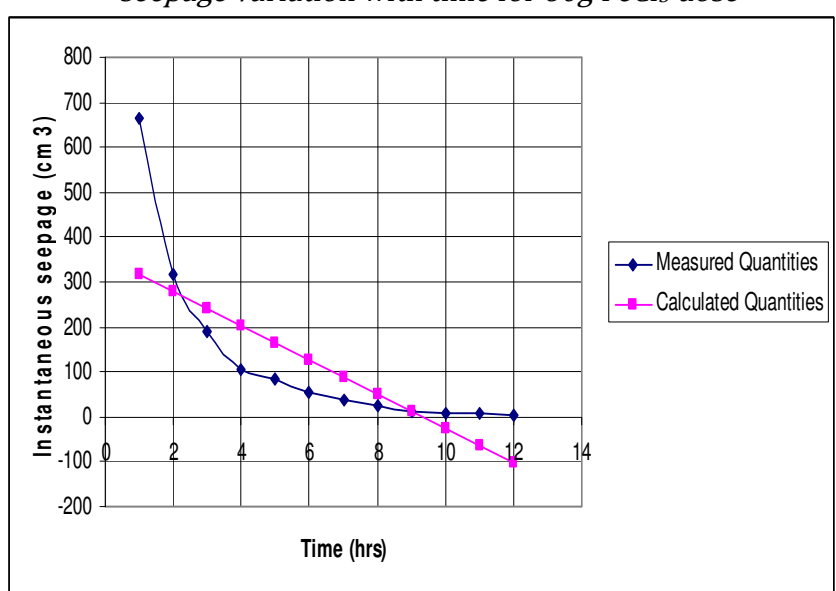

Figure 8: Comparison of measured and calculated Instantaneous seepage variation with time for $90 \mathrm{~g} \mathrm{FeCl}_{3}$ dose

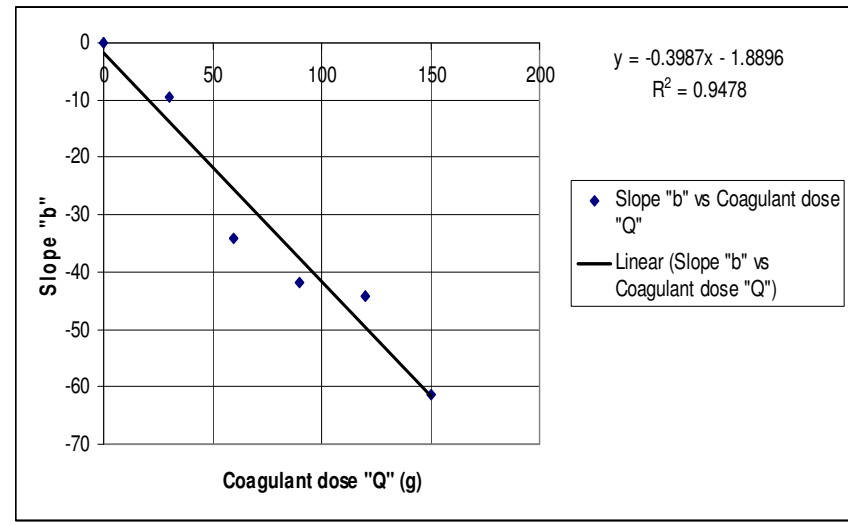

Figure 3: Variation of slopes with coagulant doses

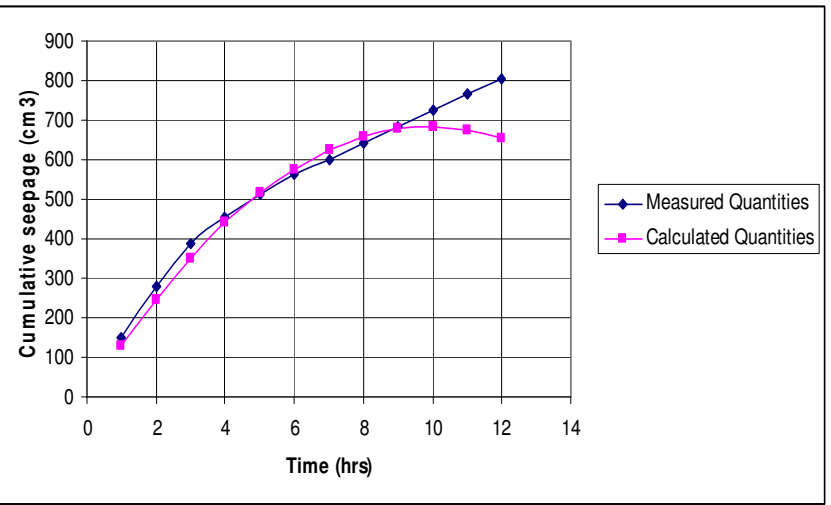

Figure 5: comparison of measured and calculated cumulative seepage variation with time for $30 \mathrm{~g} \mathrm{FeCl}_{3}$ dose

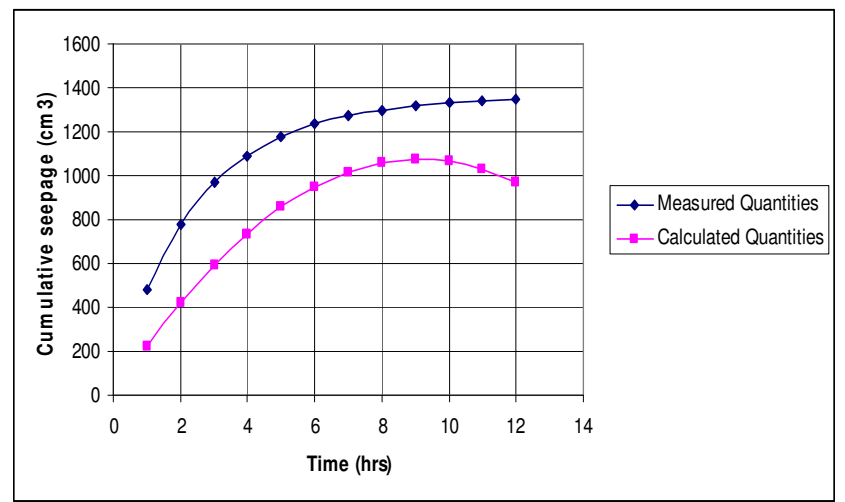

Figure 7: Comparison of measured and calculated cumulative seepage variation with time for $60 \mathrm{~g} \mathrm{FeCl} l_{3}$ dose

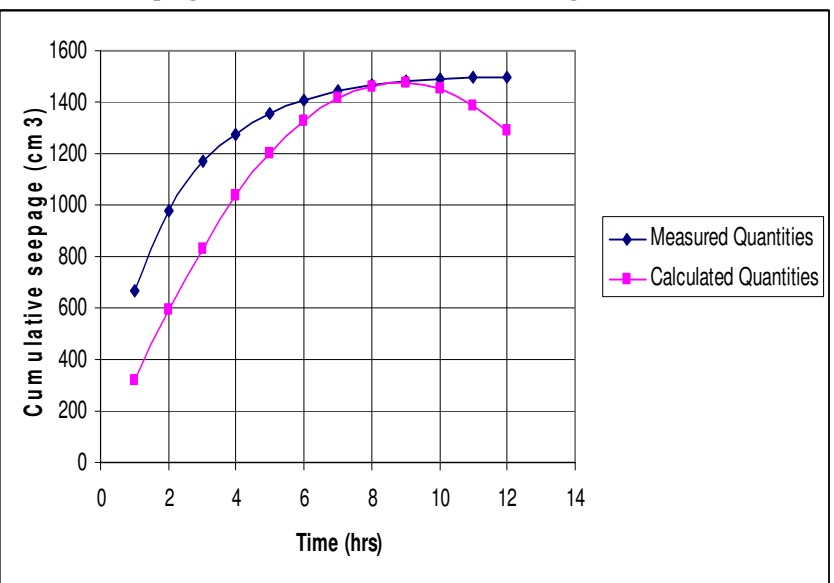

Figure 9: Comparison of measured and calculated cumulative seepage variation with time for $90 \mathrm{~g} \mathrm{FeCl}_{3}$ dose 


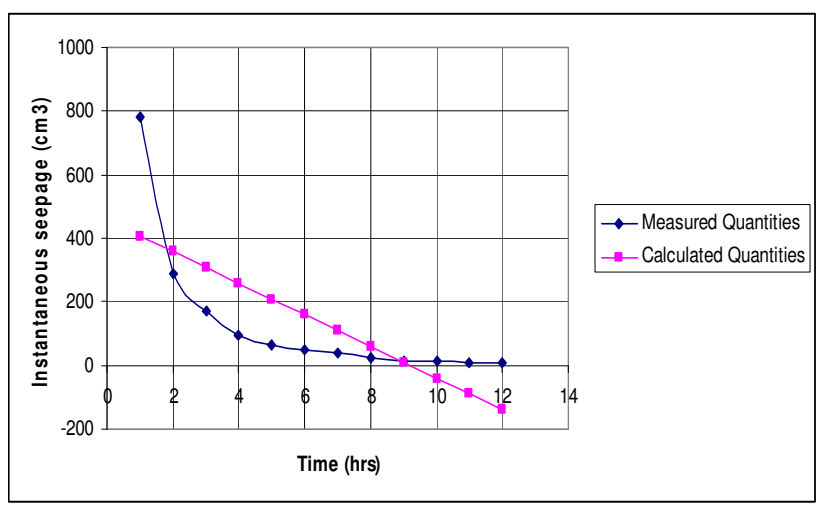

Figure 10: Comparison of measured and calculated Instantaneous seepage variation with time for $120 \mathrm{~g} \mathrm{FeCl}_{3}$ dose

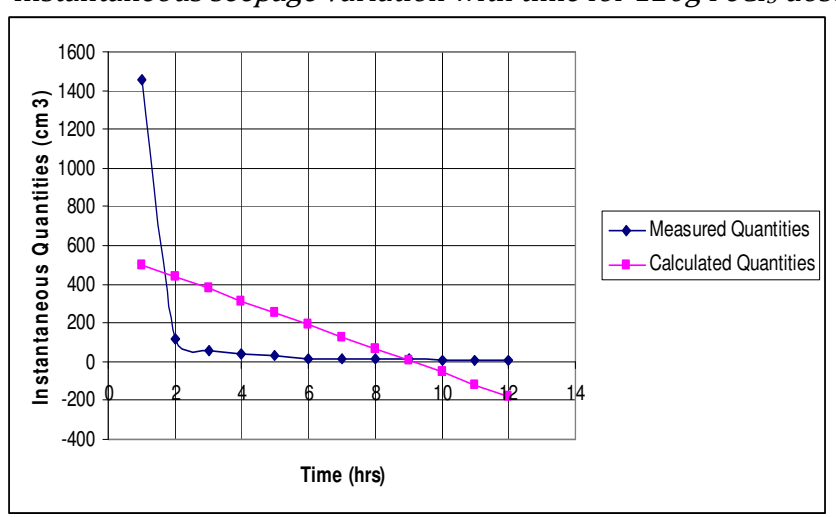

Figure 12: Comparison of measured and calculated Instantaneous seepage variation with time for $150 \mathrm{~g} \mathrm{FeCl}_{3}$ dose

\section{RESULTS AND DISCUSSIONS}

The model of (14) was used for verification. At a given dose of coagulant $Q$, different times ranging from $t=1,2,3, \ldots \ldots . .12$ hours were substituted to determine the calculated quantities of seepage $s g_{c}$. Measured quantities of seepage $s g_{m}$ were regressed on the calculated quantities $s g_{c}$, and the coefficient of correlation $r$, gives a measure of adequacy of the model. Usually an $r$-value from 0.60 and above is good. It was discovered that the coefficient of correlation between $s g_{m}$ and $s g_{c}$ when $30 \mathrm{~g}$ of $\mathrm{FeCl}_{3}$ conditioner was used is $r=0.860$, it is 0.844 , $0.781,0.722$ and 0.535 for $60 \mathrm{~g}, 90 \mathrm{~g}, 120 \mathrm{~g}$ and $150 \mathrm{~g}$ coagulant doses used respectively. These results show that $r$-value between $s g_{m}$ and $s g_{c}$ decrease with increase in coagulant dose used at any time.

Final moisture content of sludge was computed at the end of experiment after dewatering. Results revealed that as much as $86.69 \%$ moisture was present in the sludge with no coagulant added (i.e. control experiment). It was $69.47 \%, 57.32 \%, 54.01 \%, 52.79 \%$, and $47.81 \%$ respectively when $30 \mathrm{~g}, 60 \mathrm{~g}, 90 \mathrm{~g}, 120 \mathrm{~g}$, and $150 \mathrm{~g} \mathrm{FeCl}_{3}$ doses were used, with a range of

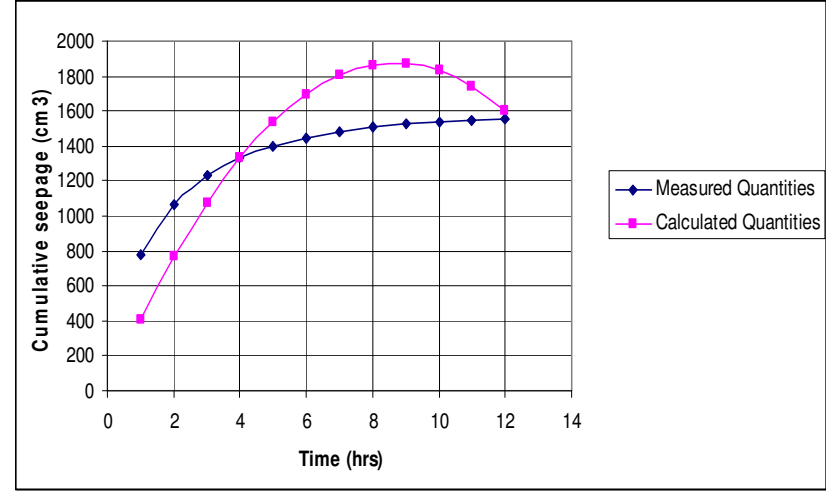

Figure 11: Comparison of measured and calculated cumulative seepage variation with time for $120 \mathrm{~g} \mathrm{FeCl}_{3}$ dose

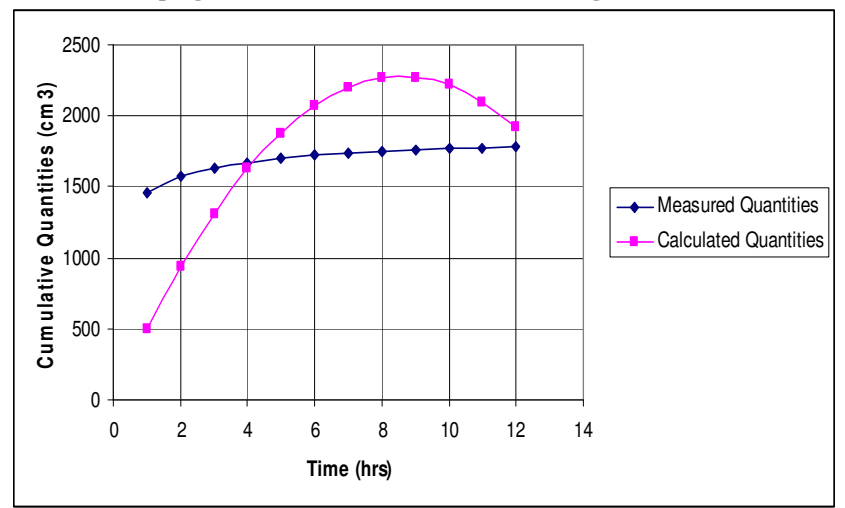

Figure 13: Comparison of measured and calculated cumulative seepage variation with time for $150 \mathrm{~g} \mathrm{FeCl}_{3}$ dose

$38.88 \%$. These results indicate remarkable reduction of moisture as the quantity of conditioner in the sludge is increased and are shown in Table 2.

Dewaterability enhancement ratio increases with increase in coagulant doses. The results is $1: 1$ for control experiment, 1:27.72, 1:46.59, 1:51.72, 1:53.62, and 1:61.34 for $30 \mathrm{~g}, 60 \mathrm{~g}, 90 \mathrm{~g}, 120 \mathrm{~g}$, and $150 \mathrm{~g} \mathrm{FeCl}$ doses. These results shown in table 3 , without doubt reflect the high efficacy of conditioners in the dewaterability of sewage sludge. The curve show that dewaterability enhancement increases as the coagulant doses increase.

Plots of the relationship between cumulative measured and calculated seepage variation with coagulant doses are shown in Figures 5, 7, 9, 11 and 13 and the curves depict some degree of affinity between the measured and calculated values.

From the data on table 4 , the p-values corresponding to $30 \mathrm{~g}, 60 \mathrm{~g}, 90 \mathrm{~g}, 120 \mathrm{~g}$, and $150 \mathrm{~g}$ are $0.000,0.001$, $0.003,0.008$ and 0.073 respectively. Since p-values for $30 \mathrm{~g}, 60 \mathrm{~g}, 90 \mathrm{~g}$ and $120 \mathrm{~g}$ doses are less than $\alpha=0.05$, and based on the decision rule, we conclude that the model $s g=a+b t$ is adequate. Only the $150 \mathrm{~g}$ dose has a value greater than 0.05 and disagrees that the model $s g=a+b t$ is adequate, though this is not 
significant since it represents only $20 \%$ of the data tested.

\section{CONCLUSION}

The model $s g=\left(\lambda_{1}+\lambda_{2} Q\right)+\left(\beta_{1}+\beta_{2} Q\right) t$ is good, but its deficiency lies in the fact that the coefficient of correlation between measured and calculated quantities of seepage at specified coagulant doses decrease with increase in coagulant dosage. This means that above the dosage of $150 \mathrm{~g}, r$-value may fall below 0.50 which dissatisfies the model $s g=(40.3921+3.471 Q)-(1.882+0.3988 Q) t$.

Nevertheless, statistical test parameter, "p-value" tested at $95 \%$ confidence limit justifies the adequacy of the model. Further research is recommended so as to improve on this already existing model. Finally, it is observed that the higher the quantity of coagulant used, the higher the dewaterability of sewage sludge. The only disadvantage of using conditioners in dewatering sludge lies in the fact that the effluent cannot be recycled for consumption because of the toxic Ferric Chloride that has been used as conditioner. Nevertheless, the effluent can still be used for irrigation purposes after less elaborate treatment has been effected.

\section{REFERENCES}

[1] Nakano, T., (2000), Achievements of rural facilities. In: Creation of New Water Environment. Tokyo: Noubunkyou.

[2] Verrelli, D. I., Dixon, D. R., Scales, P. J. (2009). Effect of coagulation conditions on the dewatering properties of sludges produced in drinking water treatment, Colloids and surfaces A: Physicochemical and Engineering Aspects, Vol. 348, 14 - 23.

[3] Landman, K.A., White, L.R., (1994), Solid/liquid separation of flocculated suspensions. Adv. Colloid Interface Sci. 51, 175-246

[4] Concha, F., Bustos, M. C., Barrientos, A. (1996). Phenomenological theory of sedimentation. In: Tory,
E. (Ed.), sedimentation of small particles in a viscous fluid. Southampton: Computational Mechanics Publications.

[5] Burger, R., Concha, F., (1998). Mathematical model and numerical simulation of the settling of flocculated suspensions. Int. J. Multiph. Flow 24, $1005-1023$.

[6] Burger, R. Bustos, M. C., Concha, F., (1999). Settling velocities of particulate systems: Phenomenological theory of sedimentation processes: Numerical simulation of the transient behaviour of flocculated suspensions in an ideal batch and continuous thickener. Int. J. Miner. Process. 55, 267 - 282.

[7] Burger, R. Wendland, W. R., Concha, F. 2000c. Model equations for gravitational sedimentation consolidation processes. Z. Angew. Math. Mech. 80, $79-92$.

[8] Bustos, M. C., Concha, F., Burger, R., Tory, E. M., (1999). Sedimentation and thickening, Dordrecht: Kluwer Academic Publishing.

[9] Garrido, P., Burger, R., Concha, F., (2000), Settling velocities of particulate systems: II comparison of the phenomenological sedimentation consolidation model with published experimental results. Int. J. Miner. Process. 60, 213 - 227.

[10] Burger, R., Karlsen, K. H. (2001), On some upwind difference scheme for the phenomenological sedimentation consolidation model. J. Eng. Math. 41, $145-166$.

[11] Garrido, P., Burgos, R., Concha, F., Burger, R., (2004), Settling velocities of particulate systems: 13. A simulator for batch and continuous sedimentation of flocculated suspensions. Math. Comput. 34, 45 - 75

[12] Burger, R., Evje, S., Karlsen, K. H. Lie, K-A., (2000b), Numerical methods for the simulation of the settling of flocculated suspensions. Chem. Eng. J. 80, 90 104.

[13] Engquist, B., Osher, S., (1980), Stable and entropy satisfying approximations for transonic flow calculations. Math. Comput. 34, 45 - 75.

[14] Evje, S., Karlsen, K. H., 2000. Monotone difference approximations of BV solutions to degenerate convection diffusion equations. SIAM J. Numer. Anal. 37, 1838 - 1860. 